\title{
Announcements
}

\section{6th International Congress on Hormonal Steroids}

The international organizing committee of the International Study Group for Steroid Hormones has chosen Israel as the venue for the 6th International Congress on Hormonal Steroids. The congress will be held in Jerusalem September 5-10, 1982.

The cha basic aspects of the biology of the steroid hormones and vitamin D. Enquiries for further information should be sent to The Secretariat, P.O. Box 29784, Tel Aviv 61 297, Israel.

\section{Third International Meeting on Human Prolactin}

Athens, Greece, October 26-28, 1981

This meeting will be held under the auspices of the International Society of Neuroendocrinology.

\section{Topics}

Circulating forms of PRL; recent developments in RİA/bioas-say techniques; distribution and internalization of PRL receptors; effects of prolactin on brain, breast, and gonads; control of PRL secretion; sex steroids and neurotransmitters as modulators of PRL release; PRL and neurotransmitters in the portal blood; recent developments in CNS dopaminergic pathways and dopamino-

mimetic drugs; in vitro studies of PRL secretion from normal and tumorous lactotropes; pathobiology of prolactinomas; neuroradi-ological developments in the diagnosis of prolactinomas; long-term follow-up of medically or surgically treated micro/macro-prolactinomas; prolactinomas and pregnancy.

Keynote Speakers

Following is a partial list of participating scientists:
L. Annunziato M. Batrinos G. Bertrand J. Boissier
$\begin{array}{lll}\text { P.G. Crosignani R. Ethier } & \text { E. Fluckiger H. Friesen }\end{array}$

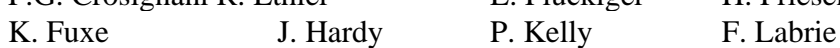
$\begin{array}{lll}\text { K. Fuxe } & \text { J. Hardy } & \text { P. Kelly } \\ \text { D. Ludecke } & \text { R. McLeod } & \text { A.S. McNeilly F. Peillon }\end{array}$

$\begin{array}{llll}\text { J. Porter } & \text { B. Posner } & \text { F. Robert } & \text { C. Robyn }\end{array}$

A. Tixier-Vidal $\quad$ G. Tolis $\quad$ K. Von Werder

Papers

Abstracts for all presentations - plenary sessions and poster exhibits $-150-250$ words, $15 \mathrm{~cm}$ wide $\times 23 \mathrm{~cm}$ long, should be received by Dr. G. Tolis no later than August 10 , 1981. If accepted, these will be published in the Proceedings volume and in the October issue of Neuroendocrinology Letters.

Organizing Committee

G. Tolis (chairman), F. Labrie, F. Pavlatos, C. Robyn, E. Tho-mopoulou (local chairperson). For further information, please contact: Dr. George Tolis, McGill University Clinic, Royal Victoria Hospital, 687 Pine Avenue West, Montreal, Qué. H3A 1A1, Canada. Telephone: (514) 845-3782, telex: 05-827899. 